\title{
PASSENGER CAR EQUIVALENTS ON DOWNGRADES OF TWO-LANE ROADS
}

\author{
MARKO SUBOTIĆ ${ }^{\star}$, ŽELJKO STEVIĆ ${ }^{2}$ \\ EDIS SOFTIĆ ${ }^{3}$, VELJKO RADIČEVIĆ \\ ${ }^{1,2}$ Faculty of Transport and Traffic Engineering, University of East Sarajevo, \\ Doboj, Bosnia and Herzegovina \\ ${ }^{3}$ Faculty of Technical Sciences, University of Bihac, Bihac, \\ Bosnia and Herzegovina \\ ${ }^{4}$ Technical College of Applied Sciences, Urosevac (Leposavic), Serbia
}

Received 13 January 2020; accepted 7 April 2020

\begin{abstract}
In this paper, empirical research about Passenger Car Equivalents (PCEs) on the longitudinal downgrade of two-lane roads in Bosnia and Herzegovina has been conducted in order to determine the influence of vehicle structure under free traffic flow conditions. The research has been carried out considering the classes of vehicles at cross-sections on the downgrade of two-lane roads. As a result, the negative influence of vehicle structure under free traffic flow conditions using passenger car equivalents (PCEs) has been determined. The results show that on the downgrade of two-lane roads, the value of passenger car equivalent decreases from the level terrain to the boundary minimum value for the determined downgrade $g=-3.00 \%$, after which its value starts to increase slightly. Based on the obtained values, the models calibrated with a second-degree polynomial have been developed to determine the average value of passenger car equivalent as a function of its boundary value. The paper also compares the results obtained by the developed models with the models from the Highway Capacity Manual under free traffic flow conditions. In addition, models for the percentage values of $\mathrm{PCE}_{15 \%}, \mathrm{PCE}_{50 \%}$ and $\mathrm{PCE}_{85 \%}$ have been established.
\end{abstract}

Keywords: passenger car equivalent, traffic operation, two-lane road.

* Corresponding author. E-mail: marko.subotic@sf.ues.rs.ba

Copyright (C) 2020 The Author(s). Published by RTU Press

This is an Open Access article distributed under the terms of the Creative Commons Attribution License (http://creativecommons.org/licenses/by/4.0/), which permits unrestricted use,

distribution, and reproduction in any medium, provided the original author and source are credited. 


\section{Introduction}

Passenger Car Equivalent (PCE) is used exclusively to convert a heterogeneous traffic flow into an equivalent homogeneous flow composed solely of passenger cars. In traffic engineering, the calculation of equivalents is particularly important for determining the capacity and level of service on the roads, since inclusion of these values provides a relevant indicator of the impact of commercial vehicles (CV) on road infrastructure. The category of commercial vehicles (light vehicles, heavy-duty vehicles, buses and auto trains) includes all motor vehicles, which do not belong to the class of passenger cars according to their physical driving and dynamic characteristics in the conditions of road network operation. Commercial vehicles occupy more space than passenger cars, and driving and dynamic characteristics of these vehicle classes are less favourable compared to the class of passenger cars. Based on the studies previously conducted in the world, heavy vehicles are considered to have a significant influence on the conditions of movement of other vehicles in the traffic flow, as well as psychological impact on the drivers of those vehicles (Garbarino, Guglielmi, Sannita, Magnavita, \& Lanteri, 2018). The problem arises in the analyses, i.e. the application of the HCM (Highway Capacity Manual) in local conditions, where the impact of commercial vehicles on the roads, i.e. PCE, is underestimated or overestimated due to the saturation of certain road sections.

There are three basic traffic factors affecting the capacity of road sections, namely, vehicle length, driving and dynamic characteristics of the vehicles and driver behaviour (Brackstone, McDonald, \& Sultan, 1999; Chandra \& Sikdar, 2000). As the vehicle length increases, the travel time unit of the vehicle progressively increases in general (Bhatt \& Patel, 2017). Cunagin and Messer (1983) studied steep grades used in the initial versions of HCM. Considering driving and dynamic characteristics of vehicles, Rakha and Lucic (2002) studied a random sample of trucks in Troutville at a measurement station on the I-81 in Virginia, where the average ratio of power and mass was $79.2 \mathrm{~kg} / \mathrm{kW}(130 \mathrm{lb} / \mathrm{hp})$ with standard deviation of $27.4 \mathrm{~kg} / \mathrm{kW}(45 \mathrm{lb} / \mathrm{hp})$. Then, the research was enhanced with a model modified for typical estimation of acceleration level of different vehicles, which is a realistic representation of the truck acceleration behaviour when delivering engine power that is dependent on engine speed performance in estimating typical acceleration (Fadhloun, Rakha, Loulizi, \& Abdelkefi, 2015). In addition, based on the findings of several studies, HCM-2000 (TRB, 2000) recommends that the average ratio of power and mass be between $76.1 \mathrm{~kg} / \mathrm{kW}$ and $90.4 \mathrm{~kg} / \mathrm{kW}$.
Passenger Car

Equivalents on Downgrades of Two-Lane Roads 
Increasing capacity in road engineering has become an important path to solving traffic problems (Subotić, Stević, Ristić, \& Simić, 2020). Road conditions are an additional reason to investigate the effects on PCE values, as these factors are the basis for engineering judgment in the decision-making process (Stanković, Stević, Das, Subotić, \& Pamučar, 2020). The longitudinal downgrade can have a significant effect on the change in PCE values (Subotić \& Tubić, 2017). Studies on PCE values in a free flow as a function of longitudinal downgrade are more recent and are related to the need to determine time headways and to identify the capacity of two-lane roads, especially for heavy vehicles. In addition, significant changes in PCE are reflected on longer but steeper downgrades. This trend is strongly related to the variability of PCE in relation to the length and degree of the downgrade (TRB, 2010, 2016). Considering the above-said, the need for development of a new empirical model aimed at determining the influence of commercial vehicles (CV) on vehicle movement in the conditions of free traffic flow in local conditions in the territory of Bosnia and Herzegovina becomes obvious.

The paper is structured as follows: Section 1 provides a brief description of the related papers in this area, in addition to the references covered in the introductory part. The detailed methodology used in this study to obtain PCE values is given in Section 2. The results of research obtained using the developed research models and their discussion are presented in Section 3. Finally, the last section provides concluding considerations with specific values, i.e. paper contribution and directions for further research.

\section{Literature review}

Scientific papers based on the study of PCE mainly deal with the estimation of PCE values in relation to different categories of vehicles under different traffic and road conditions (Al-Kaisy, Hall, \& Reisman, 2002; Biswas, Chandra, \& Ghosh, 2017; Gautam, Das, Rao, \& Tiwari, 2018; Raj, Sivagnanasundaram, Asaithambi, \& Ravi Shankar, 2019; Rakha \& Lucic, 2002; Webster \& Elefteriadou, 1999; Zhou, Rilett, Jones, \& Chen, 2016). Cunagin and Messer (1983) use the ratio of delay as a measure of performance to evaluate PCE of heavy vehicles on multilane roads. Some studies (Sumner, Hill, \& Shapiro, 1984; Webster \& Elefteriadou, 1999) use the number of vehicles per hour to express the density equivalent, since density is a function of the flow of vehicles and their length. There are a great number of studies based on the method of estimating PCE for a mixed traffic flow as a function of vehicle surface (length $\times$ width) and speed (Al-Kaisy, Jung, \& Rakha, 2005; Chandra \& 
Sikdar, 2000; Kumar, Arkatkar, Joshi, \& Dhamaniya, 2017). Based on the data obtained from a speed detector in the United Kingdom (Al-Obaedi, 2016) on M-25 and M-42 motorways, it has been found that PCE values vary as a function of traffic flow speed due to different lengths of heavy vehicles and passenger cars. Elefteriadou, Torbic, \& Webster (1997) also use average speed as a performance measure, while research by Webster \& Elefteriadou (1999) determines density as a performance measure for establishing PCE values. This study advances the research by Sumner et al. (1984) that includes a wide range of road conditions using the number of vehicles per hour to express the density equivalent, since density is a function of the flow of vehicles and vehicle length. In addition, a study conducted on A-22 Brenner Freeway in Italy (Giuffrè, Granà, Mauro, Silva, \& Chiappone, 2015) has found that microsimulation could be useful in assessing the impact of heavy vehicles on the quality of traffic flow. The study shows that PCE values are small at low vehicle flow rates since a small number of passenger vehicles reduce the potential impact of heavy vehicles on them. However, some studies (Demarchi \& Setti, 2003; Sumner et al., 1984) provide a broad overview of studies on heterogeneous traffic flow models and conclude that linear density measurement is not adequate for a mixed vehicle category and that sections of vehicle movement should be measured. In addition, many studies have concluded that a simple definition of PCE is not applicable and that the value of equivalents depends on flow composition, saturation degree, location, etc. A more recent study (Anwaar et al., 2011) presents an alternative methodology for estimating PCE based on video-recorded traffic data. The methodology allows for site-specific PCE values to be calculated based on the prevailing traffic characteristics. According to Al-Kaisy et al. (2002, 2005), a key feature of this research approach is the queue discharge flow (QDF) factor as a criterion for the development of PCE for heavy vehicles during congestion. QDF (queue discharge capacity) is a criterion for determining the quantity of effects of heavy vehicles, which represents driving mechanism on roads. A similar equivalence criterion (Yeung, Wong, \& Secadiningrat, 2015) is given in the methodology for PCE adjustment to fast and slow lanes, where flows converge after PCE adjustment. In this study, the equivalence criterion is given for the capacity of traffic lanes during peak traffic load. Several studies (Bham \& Benekohal, 2004) use the percentage of a section occupied by vehicles as a function of speed to better present traffic conditions of congestion, when traffic flow is composed of vehicles of heterogeneous length. The research (Anwaar et al., 2011) uses the data obtained from a microloop detector to estimate PCE using spatial lagging headways. The results of the previous studies confirm that PCE values differ for each country due to differences in
Passenger Car Equivalents on Downgrades of Two-Lane Roads 
driving and dynamic characteristics of vehicles, drivers' mental abilities, road and environmental conditions, flow structure conditions, etc.

According to the study by Rahka \& Lucic (2002), which distinguishes seven different road conditions and types of pavement (concrete pavement excellent condition, concrete pavement good condition, concrete pavement bad condition, asphalt pavement good condition, asphalt pavement proper condition, asphalt pavement bad condition and pavement under snow), the value of PCE on good pavements is less variable. Reduced variability is attributed to the coefficients of friction and rolling (Nunic, Ajanović, Miletić, \& Lojić, 2019), which demonstrate almost the same values on good and standard pavements (proper asphalt). Excellent concrete pavement showed an improvement in the coefficient of friction and rolling as compared to the standard pavement. For this reason, PCE for concrete pavements in excellent condition is always lower than PCE for proper asphalt. Snow-covered pavements generally increase PCE values as compared to standard pavements.

\section{Methodology}

The research methodology consists of procedures for selecting measurement locations, empirically measuring headways, synthesizing and analysing the data collected, as well as determining PCE values at given cross-sections, as shown in Table 1.

\subsection{Topicality of the Research}

In the studies conducted on longitudinal gradients of two-lane roads, the negative impact of heavy vehicles on PCE values on the longitudinal gradient has been demonstrated, where by increasing the gradient, PCE values also increase (TRB, 2000; Sorensen, 1998; Subotić \& Tubić, 2017). This claim applies to all non-passenger vehicles. The problem arises in analyses of PCE values in local conditions, where the impact of heavy vehicles on roads is underestimated or overestimated.

The paper mainly aims at demonstrating that the value of PCE on the downgrade of two-lane roads is in a complex functional dependence on flow structure, driving and dynamic characteristics of vehicles and drivers, and especially technical and exploitation characteristics of the road. It is also expected that the default fluctuations and changes of PCE can be verified in local conditions. Considering PCE values, the existing scientific literature has shown variable values for PCE. It is possible to obtain the applied PCE values used in the analysis of capacity and the 
Level of Service using the procedures for traffic and technical sizing Passenger Car and evaluation of functional parts of road network. By thoroughly studying the PCE values, which express the influence of commercial vehicles on vehicle movements in the traffic flow, it is possible to suggest PCE values for local conditions. This study is based on the results of empirical research, and the most significant tasks in this paper refer to the operationalisation and adaptation of the aforementioned parameters that have been investigated for practical use in local conditions.

\subsection{Method for determining PCE values}

The most commonly used method for determining PCE values is the method of relative time headway relations in the process of vehicle queue discharge. The method was developed by Greenshields in 1947 and is known in literature as the basic method for determining time headways. The concept of this method is based on Eq. (1):

$$
P C E_{i}=\frac{H_{i}}{H_{\mathrm{PC}}},
$$

$P C E_{i}$ - passenger car equivalent of $i$ class of vehicles;

$H_{i}$ - mean value of headways of $i$ class of vehicles;

$H_{\mathrm{PC}}$ - mean value of headways for passenger cars.

The concept that uses the parameter of headways (temporal or spatial parameter) is based on the segmentation of space occupied by different vehicles. Sorensen (1998) investigated the impact of commercial vehicles on the Danish roads. The research was conducted on five sections of the road near Copenhagen. The methodology is based on the follow-up time (gap) since it is directly related to capacity. Krammes \& Crowley (1986) analysed heterogeneous traffic flow, on the basis of which they formulated Eq. (2) considering differences in the headways between trucks and other vehicles, as follows:

$$
P C E=\frac{(1-p)\left(h_{p t}+h_{t p}-h_{p p}\right)}{h_{p p}},
$$

$p$ - percentage of trucks in a heterogeneous traffic flow;

$h_{p t}$ - average headway, measured in seconds, for heavy vehicles following passenger cars;

$h_{t p}$ - average headway, measured in seconds, for passenger cars following heavy vehicles;

$h_{p p}$ - average headway, measured in seconds, for passenger cars following passenger cars. 
Table 1. Summary of methodological settings applied in the research

\begin{tabular}{|c|c|}
\hline $\begin{array}{l}\text { Applied } \\
\text { methodology }\end{array}$ & $\begin{array}{l}\text { The basic method for relative time headway relations by observing five vehicle } \\
\text { categories (PV, LV, HDV, BUS, and AT) }\end{array}$ \\
\hline $\begin{array}{l}\text { Recording } \\
\text { technique }\end{array}$ & Semi-automatic, using special measuring equipment \\
\hline \multirow[t]{2}{*}{$\begin{array}{l}\text { Location } \\
\text { selection }\end{array}$} & $\begin{array}{l}\text { Physical elements: standard two-lane (main) road with two lanes of width } \\
\text { of min } 3.00 \mathrm{~m} \text {; the existence of constant longitudinal downgrades } \\
\text { on the approaches not shorter than } 1000 \mathrm{~m} \text { with allowed deviation } \\
\text { up to } \pm 0,5 \% \text {; the radius of the horizontal curve is straight; the visibility length } \\
\text { for safe overtaking is complete; no road works in the measurement area; } \\
\text { overtaking is prohibited and there are no settlements around; there are no } \\
\text { intersections before and after measurement locations }\end{array}$ \\
\hline & $\begin{array}{l}\text { Traffic criteria: high traffic load, higher percentage of commercial vehicle } \\
\text { participation ( } 15 \% \text { and more), a lane with no influential factor of turning } \\
\text { movements, no impact of parking or bus stops, peak and off-peak period } \\
\text { recording }\end{array}$ \\
\hline Data processing & $\begin{array}{l}\text { Based on the average values of individual locations and the total average } \\
\text { value, the analysis neglects the influence of vehicle position in a queve } \\
\text { (which is not common in the world literature) }\end{array}$ \\
\hline
\end{tabular}

The following elements and criteria (Table 1) were used defining research methodology and techniques, site selection and data processing methods.

Measurement locations were selected on two lane roads. The selected cross-sections were defined at the locations and the arithmetic mean of the given downgrades was determined at a distance of $1000 \mathrm{~m}$ from the cross-sections. The operator's measurements were carried out at the measurement locations on the longitudinal gradient in a direction and horizontally, but the measurement locations tended to be on the sections where no overtaking was permitted. Measurements were taken in the morning and afternoon, when there were no influential factors of peak loads, implying a "realistic" traffic flow. Recording was done visually on the measuring sections. Then, the obtained PCE values were compared to determine the difference in values. Measuring locations with longitudinal downgrade are given in Figure 1.

\subsection{Analysis of sample size and critical headway}

A study on PCE values (Al-Kaisy et al., 2002) found that the distribution of PCEs could be approximated by the Gaussian distribution. Certain characteristics of the Gaussian distribution can be used to determine the required sample size. If the sample of $n$ vehicles has a 




Passenger Car

Equivalents on Downgrades of Two-Lane Roads

Figure 1. Measuring locations with the longitudinal downgrade in Bosnia and Herzegovina

random distribution of PCEs with the mean $\mu$ and variance $\sigma^{2}$, then variable $x$, which represents the arithmetic mean of the sample, will also have a normal distribution with the mean $\mu$ and variance $\sigma^{2} / n$. $U-$ coefficient for a certain level of reliability, where the values of $U$ and $K$ are given in Table 2 .

All values of a random variable are within the six standard deviations given in the table, and a negligible number of values (per $0.15 \%$ from the interval $+\infty$ to $-\infty$ ) remain beyond this interval. If we want to determine the required sample size on the basis of the above equations, we need to know the standard deviation of PCE values, which is unfamiliar to us 
Table 2. $K$ and $U$ values for a certain level of reliability

\begin{tabular}{cccc}
\hline $\begin{array}{c}\text { Level of } \\
\text { reliability, \% }\end{array}$ & $\boldsymbol{K}$ & $\begin{array}{c}\text { PCE values in } \\
\text { percent }\end{array}$ & $\boldsymbol{U}$ \\
\hline 68.27 & 1.00 & & \\
90.00 & 1.65 & $50 \%$ & 0.00 \\
95.00 & 1.96 & $15 \%$ or $85 \%$ & 1.04 \\
95.47 & 2.00 & $7 \%$ or $93 \%$ & 1.48 \\
99.00 & 2.58 & $5 \%$ or $95 \%$ & 1.67 \\
99.73 & 3.00 & & \\
\hline
\end{tabular}

before making the measurements. For the assumed standard deviation value $\sigma=0.2,0.4,0.6,0.8,1.0$, and 1.2 and the acceptable deviation limit $e=0.1$, the required sample size for the $e$-level reliability of $90 \%$ and $95 \%$ is as shown in Table 3 .

In order to analyse the PCE values of free traffic flow, it needs to be explained by the term of critical headway, which is mainly used to determine the status of an individual vehicle in a traffic flow. Summarizing the results of studies by different authors, Lay (1984) concludes that there are three defined time zones of headways. $<2.5$ seconds - traffic flow is forced, 2.5-9.0 seconds - traffic flow is between forced and free, $>9.0$ seconds - traffic flow is free.

Table 4 gives the values of critical headways recommended by some authors of earlier editions.

The American manual HCM-2000 (TRB, 2000) uses percent timespent-following (percentage of overtake delay time) in describing the Level of Service on two-lane roads. Time-spent-following is defined as the percentage of time when a vehicle is impeded by other vehicles, and for its simplification it is determined as the percentage of time when the vehicle moves below the critical headway, in other words, as a vehicle being in a platoon. For the purposes of further analysis and research, this paper adopts a critical headway of 5.0 seconds.

Table 3. Required sample size

\begin{tabular}{ccccccccc}
\hline & \multicolumn{8}{c}{ Sample size for acceptable deviation value e $=0.1$} \\
\cline { 4 - 9 } $\begin{array}{c}\text { Reliability } \\
\text { level }\end{array}$ & $\boldsymbol{K}$ & $\boldsymbol{U}$ & $\mathbf{0 . 2}$ & $\mathbf{0 . 4}$ & $\mathbf{0 . 6}$ & $\mathbf{0 . 8}$ & $\mathbf{1 . 0}$ & $\mathbf{1 . 2}$ \\
\hline $90 \%$ & 1.65 & 0.00 & 11 & 44 & 98 & 174 & 272 & 392 \\
$95 \%$ & 1.96 & 1.04 & 15 & 61 & 138 & 246 & 384 & 553 \\
\hline
\end{tabular}


Table 4. Critical headways recommended by some authors

\begin{tabular}{ccc}
\hline Critical headway & Country & Reference \\
\hline 4.0 & Australia & Hoban, 1983, 1984 \\
4.0 & South Africa & Wolhuter, 1989 \\
5.0 & Australia & Underwood, 1963 \\
5.0 & USA & TRB, 1985 \\
6.0 & Canada & Krumins, 1988 \\
\hline
\end{tabular}

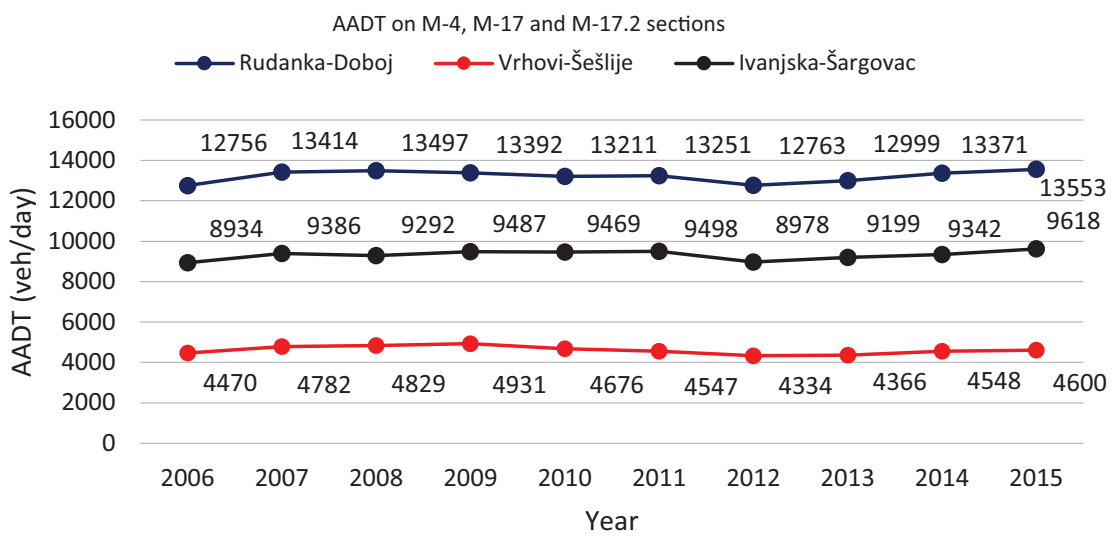

Figure 2. AADT on measurement sections of two-lane roads

In order to understand adequately the AADT (average annual daily traffic) on these sections, it is necessary to point out the flows on the sections (Figure 2), with the aim to show traffic flow conditions on the measured cross-sections of the given road sections. These sections are under free flow conditions.

\subsection{Synthesis and data analysis}

The measured time headways obtained through empirical research were recorded for five vehicle classes in a database created in Microsoft Office Excel, where further statistical processing was performed. The software, while recording time headways onto a computer, performed classification of the measured data into five classes of vehicles (Passenger Vehicles (PV), Light Vehicles (LV), Heavy-Duty Vehicles (HDV), Buses (BUS) and Auto Trains (AT)). The main goal was to collect more than 100 time headways (and therefore PCE values) for commercial vehicles in each location of the observed road cross-section.
Marko Subotić, Željko Stević,

Edis Softić,

Veljko Radičević

Passenger Car

Equivalents

on Downgrades of Two-Lane Roads 


\begin{tabular}{lccccccccccc}
\hline $\begin{array}{c}\text { Measurement } \\
\text { location }\end{array}$ & $\begin{array}{c}\text { Category } \\
\text { and number } \\
\text { of roads }\end{array}$ & $\begin{array}{c}\text { Longitudinal } \\
\text { downgrade, } \\
\text { \% }\end{array}$ & Th, s & PC & LV & HDV & BUS & AT & $\begin{array}{c}\text { All } \\
\text { CV }\end{array}$ & $\begin{array}{c}\boldsymbol{\Sigma} \text { of all } \\
\text { vehicles }\end{array}$ \\
\hline Rudanka-Doboj & $\mathrm{M}-17$ & 0.00 & 3.600 & 835 & 78 & 66 & 19 & 12 & 175 & 1010 \\
Vrhovi-Šešlije & $\mathrm{M}-17.2$ & -1.00 & 18.174 & 818 & 23 & 42 & 19 & 108 & 192 & 1010 \\
Ivanjska-Šargovac & $\mathrm{M}-4$ & -2.00 & 12.553 & 871 & 65 & 18 & 21 & 25 & 129 & 1000 \\
Ivanjska-Šargovac & $\mathrm{M}-4$ & -2.98 & 5.331 & 875 & 70 & 32 & 11 & 12 & 125 & 1000 \\
Vrhovi-Šešlije & $\mathrm{M}-17.2$ & -5.00 & 19.269 & 730 & 62 & 71 & 18 & 119 & 270 & 1000 \\
Ivanjska-Šargovac & $\mathrm{M}-4$ & -5.52 & 5.349 & 930 & 31 & 16 & 16 & 7 & 70 & 1000 \\
\hline Total & & & & 5059 & 329 & 245 & 104 & 283 & 961 & 6020 \\
\hline
\end{tabular}

The recorded number of the measured PCE values for the vehicles with average time headways on the measurement locations is given in Table 5 .

In this research on headways between passenger cars, PC-PC, value 1 was taken as a standard value of PCE, although the PCE value was not considered much for different categories of passenger cars (PC). The time headway value for passenger cars was calculated as the arithmetic mean of the time headways (Th) measured at cross-sections. For each measurement location, the PCE values were calculated for each vehicle class based on the recorded time headways using the Greenshields model applied to rural roads. Subsequently, the values of relevant statistical parameters, which include the arithmetic mean (AM) and standard deviation (SD), and the variation coefficient (VC) were determined. Vehicles in each class (LV, HDV, BUS, AT and all PV) were then classified according to PCE values into classes of 0.5 in width in order to obtain distribution of PCE values. The tabular data were used for further analysis which included determining validity and percentile values of passenger car equivalents, $\mathrm{PCE}_{15 \%}, \mathrm{PCE}_{50 \%}$ and $\mathrm{PCE}_{85 \%}$. Software for function analysis TableCurve 2D v5.01 was used for this purpose. After calculating AM, SD and VC, the PCE models for all categories of vehicles depending on the longitudinal downgrade were determined. The models are presented in the form of second-degree polynomial expressed as Eq. (3):

$g$ - downgrade;

$$
P C E=A g^{2}+B g+C,
$$

$P C E$ - passenger car equivalent;

$A, B, C$-parameters obtained by regression analysis. 
Statistical analysis showed acceptable values of the correlation Passenger Car coefficient, especially for PCE values on a larger longitudinal downgrade of roads. Determining distribution, only bell curves were analysed, namely Eqn 8003 Gaussian $(a, b, c, d)$

$r^{2}=0.60916859$ DF Adj $r^{2}=0.51720826$ FitStdErr $=0.018392266$ Fstat $=9.3518878$ $a=0.012916107 b=0.061892635$ $c=3.928184 d=2.4467837$

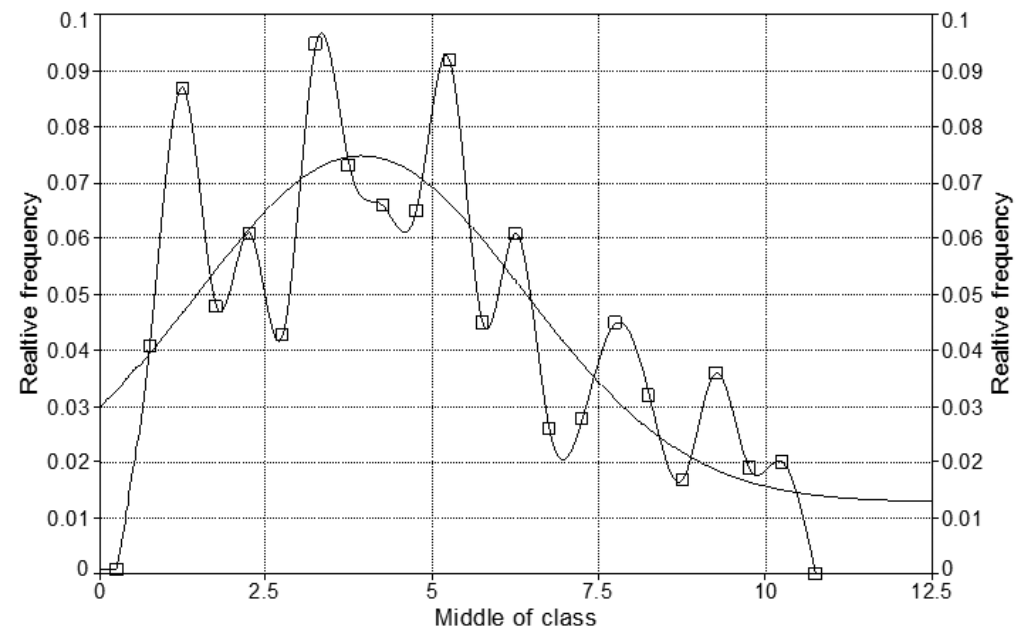

Rudanka-Doboj, distribution of $\mathrm{CV}, g=0.00 \%$ Eqn 8003 Gaussian ( $a, b, c, d$ )

$r^{2}=0.99790863$ DF Adj $r^{2}=0.99741654$ FitStdErr $=0.01669328$ Fstat $=2862.9268$ $a=-0.76628889 b=1.7562654$ $c=10.515038 d=7.887869$

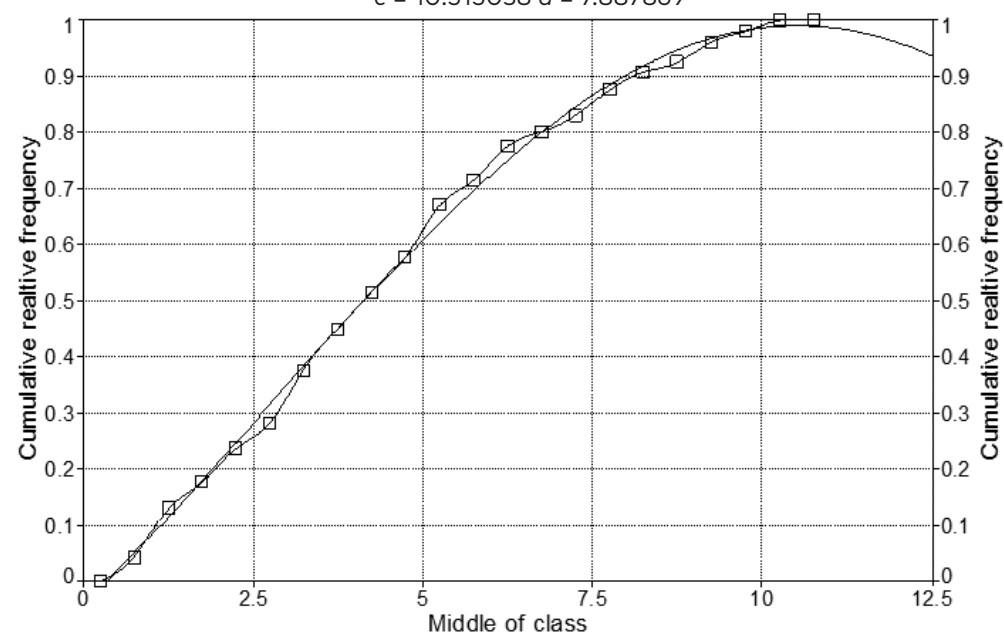

Figure 3. Empirical distribution analysis of PCE values 
the Gaussian (normal) and log-normal curve. The cumulative normal distribution in all cases was used in this study. The data grouped in statistical classes were used for further analysis to determine appropriate distribution and to determine the percentile values of $\mathrm{PCE}_{15 \%}, \mathrm{PCE}_{50 \%}$ and $\mathrm{PCE}_{85 \%}$. A cumulative function for the required root for increments 0.01 was selected to determine the values, as shown in Figure 3.

From the obtained values of function root for increment 0.01 , the values of the function root $g$ (downgrade) were extracted for PCE values of $0.15,0.50$ and 0.85 , which basically represented the percentile values for PCE. The performed statistical research was tested with the normal (Gaussian) and log-normal distribution on cross-sections. Although it is assumed that the empirical distribution of PCE values in case of sufficiently large statistical sample can be theoretically approximated with a normal distribution, it is not of importance for the scope of this research. The cumulative relative frequency is approximated by the normal (Gaussian) distribution, as shown in Figure 3.

\section{Results and discussion}

The obtained values of the correlation coefficient are satisfactory and justify the correlation expected for the obtained PCE values as a function of longitudinal downgrade. Basically, by analysing PCE values on the downgrade of two-lane roads, the highest correlation coefficient is for auto trains (AT), while the lowest value is obtained for all light vehicles (LV), which is below 0.5 . The empirical research indicates large dispersal of PCE values for light vehicles (LV), and the correlation coefficient is much higher for heavy vehicles and auto trains. Hence, the influence of traffic flow structure on the downgrade of two-lane roads implies that the presence of heavy vehicles affects less dispersal of PCE values than the classes of light vehicles. It can also explain the higher dispersal of time headways for LV on the longitudinal downgrade, the least dispersal is indicated for AT. On the downgrade, such dispersal is often interpreted as a boundary downgrade (with a value of about $3.00 \%$ ) where a continuous flow occurs with heavier vehicles. Also, PCE values by vehicle classes differ most on level terrain ( $g=0.00 \%)$, while as the downgrade increases, there is less deviation of PCE values by vehicle classes. A continuous decrease in PCE values ranges from level terrain to a downgrade of $g=-3.00 \%$, followed by a slight increase in PCE values for all four vehicle classes.

Figure 4 compares the dependency of arithmetic means of the PCE values for LV, HDV, BUS and AT. It should be noted that for two-lane roads, the last measured value is $g=-5.50 \%$, and that the PCE value 
for AT is the highest on level terrain, where it exceeds 4. Also, with a Passenger Car maximum downgrade of $g=-5.50 \%$, the value is the greatest, but does not exceed 2. What is also significant is the fact that when measuring on Downgrades of Two-Lane Roads on two-lane roads, on all longitudinal gradients and on level terrain, there is no lane for slow driving in an uphill direction, so measuring the PCE values does not have a limiting factor. In the area of downgrade $g=-1.50 \%$, and $g=-4.50 \%$, by the calibrated model, the least deviation of the PCE values by vehicle classes occurs, and they can be seen as approximately the same. Additionally, the value of PCE for AT, with increasing the downgrade, decreases more progressively to a downgrade value of $g=-3.00 \%$ compared to the PCE values for other vehicle categories. Furthermore, with a further increase in the downgrade over this value, the value increases progressively.

According to Figure 4, for $g=-5.50 \%$ it can be seen that the obtained values for LV and HDV are almost equal, while the deviation of values for BUS and AT on such a downgrade is almost negligible. In the empirical research, a small deviation of PCE values by vehicle class with increasing the downgrade can be justified by a continuous traffic flow that occurs with increasing the downgrade, regardless of different driving and dynamic characteristics of the vehicles by the adopted classes.

When analysing the obtained equivalent values for $\mathrm{PCE}_{15 \% \text {, }}$ significant deviation is observed for AT with increasing the longitudinal downgrade. In addition, for an increase in downgrade, the $\mathrm{PCE}_{15 \%}$ value for BUS is, on average, 0.10 less than for HDV, which can be considered as greater caution and continuity in driving for both vehicle classes. A significant increase in the PCE value for AT occurs only starting



Figure 4. Model for determining PCE values depending on the road downgrade for different categories of vehicles in Bosnia and Herzegovina 
Table 6. Comparison of PCE $15 \%$, PCE $50 \%$ and PCE $85 \%$ values by vehicle class

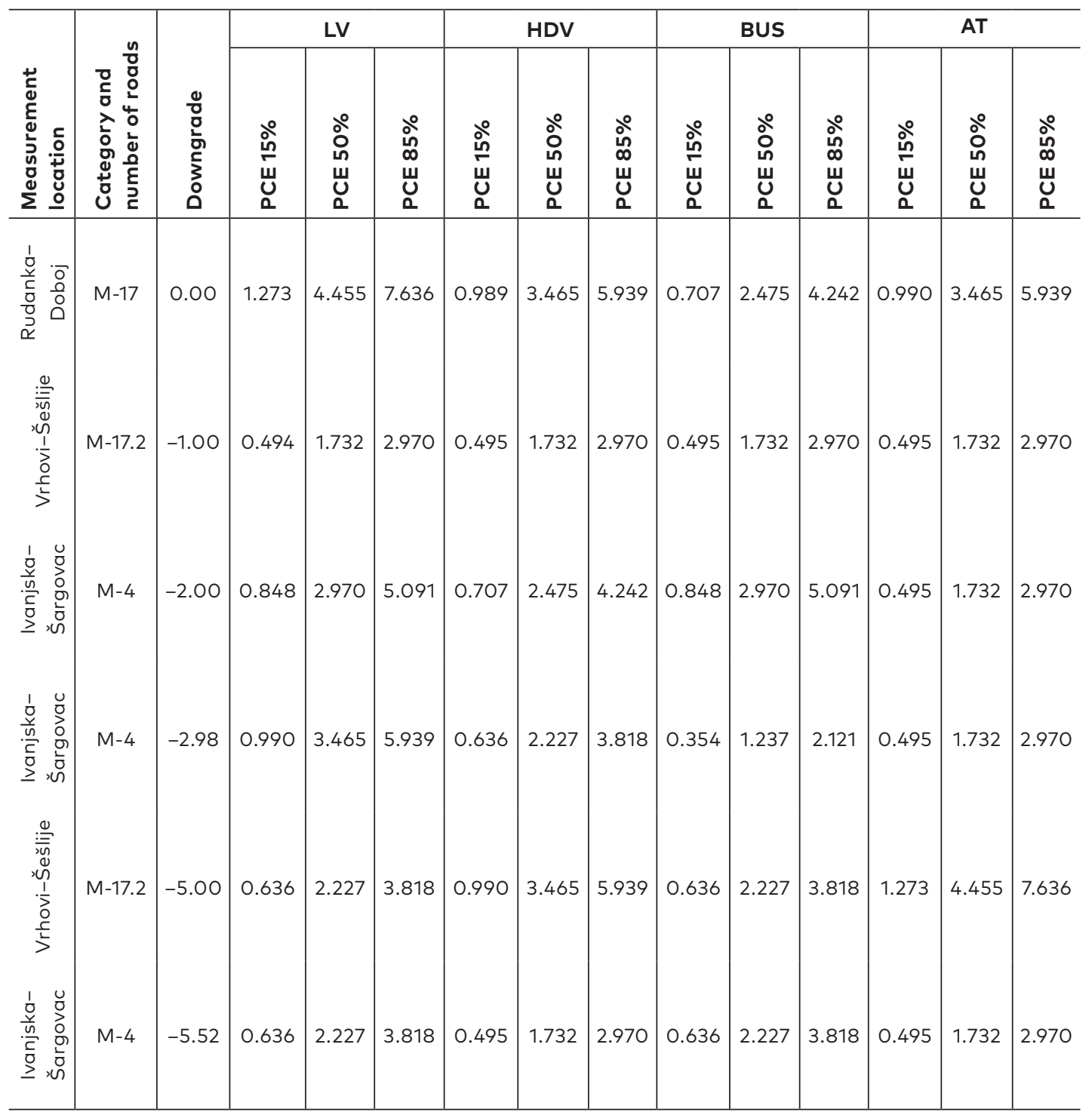

from a value of $g=-4.50 \%$. The values of $\mathrm{PCE}_{50 \%}$ imply that the largest deviation of PCE values is for the downgrade $g=-5.00 \%$, and for the downgrade $g=-2.00 \%$, PCE values vary by vehicle class from 1.50 to 3.00 . Additionally, for a value of downgrade $g=-1.00 \%$, the PCE values for all vehicle classes are equalized, thereby substantially approaching 
each other as shown in Table 6. It is evident that higher values of PCE can be assigned to overloaded vehicles (vehicles whose specific power has limit values), especially on a downgrade, and lower values of PCE can be assigned to less loaded vehicles. Also, larger differences in the PCE values are more noticeable in less loaded vehicles.

Figure 5 presents very indicative results that the difference between $\mathrm{PCE}_{15 \%}, \mathrm{PCE}_{50 \%}$ and $\mathrm{PCE}_{85 \%}$ is 2 (two) PCUs for each value of longitudinal downgrade if all commercial vehicles are observed in a real traffic flow. Additionally, for the downgrade value of $g=-3.00 \%$, the boundary downgrade value occurs, where the PCE value for commercial vehicles increases from level terrain to the boundary value and then PCE value decreases for each of the percentile levels by increasing the downgrade. The analysis of $\mathrm{PCE}_{50 \%}$, which is also the mean value for all commercial vehicles, reveals that the value ranges from $P C E_{50 \%}=2.30-4.50$. The optimistic and pessimistic forecasts of PCE values in a function of downgrade range from $P C E_{15 \%}=0.64-1.27$, and $P C E_{85 \%}=3.82-7.64$. The most prominent trend of decrease (after reaching the boundary value) and then increase in PCE values in all three cases is related to AT.

Figure 6 compares the empirically obtained PCE values for commercial vehicles depending on the longitudinal gradient with the values given in HCM-2000, HCM-2010 and HCM-2016. (TRB, 2000, 2010, 2016). According to HCM-2000, the recommended PCE values in a function of downgrade have a lower correlation coefficient due to the dispersal of the values shown in the diagram. In addition, according to

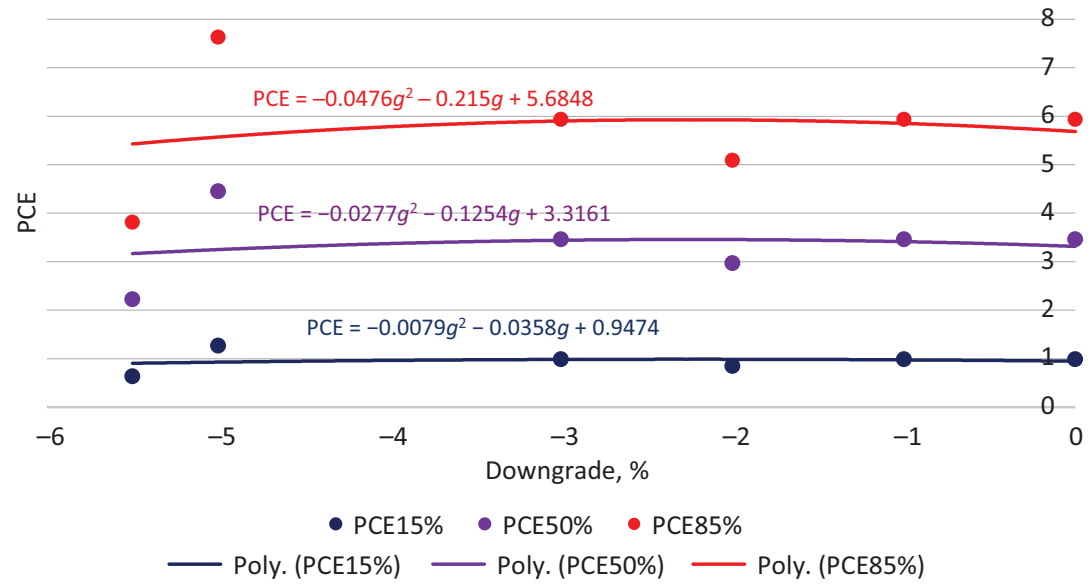

Figure 5. Comparative analysis of $P C E_{15 \%}, P C E_{50 \%}$ and $P C E_{85 \%}$ for all commercial vehicles on a downgrade 
HCM-2010 and HCM-2016, the recommended values for the given road and traffic conditions have uniform values (overlapping).

However, it can be noticed that the PCE values obtained by increasing the longitudinal downgrade are higher in our measurements than those recommended in HCM models regarding terrain and traffic conditions. This especially refers to a downgrade from level terrain to $g=-3.00 \%$, which can be explained by the fact that the US values of the impact of heavy vehicles being on a downgrade are much lower than in local conditions. It is also evident that there is no significant difference in modelling PCE values in these two HCM editions (TRB, 2010, 2016). Both models (HCM and empirically obtained model) are presented by a second-degree polynomial.

The PCE values from the last two versions of HCM (TRB, 2010, 2016) are the same. Comparing the PCE values obtained in our research with the values from HCM for the longitudinal downgrade value of about $g=-2.50 \%$ and $g=-4.50 \%$, the PCE values from HCM overlap with the values determined in our research. It is also noticeable that when increasing the longitudinal downgrade, there is an increase in PCE values for commercial vehicles in HCM models, but this increase does not exceed the equivalent value of 2.00. For the longitudinal downgrade value from $g=0.00$ to $g=-3.00 \%$, higher PCE values are obtained by our research than it is recommended by HCM-2010 and HCM-2016, as seen in the empirical model in Figure 6.

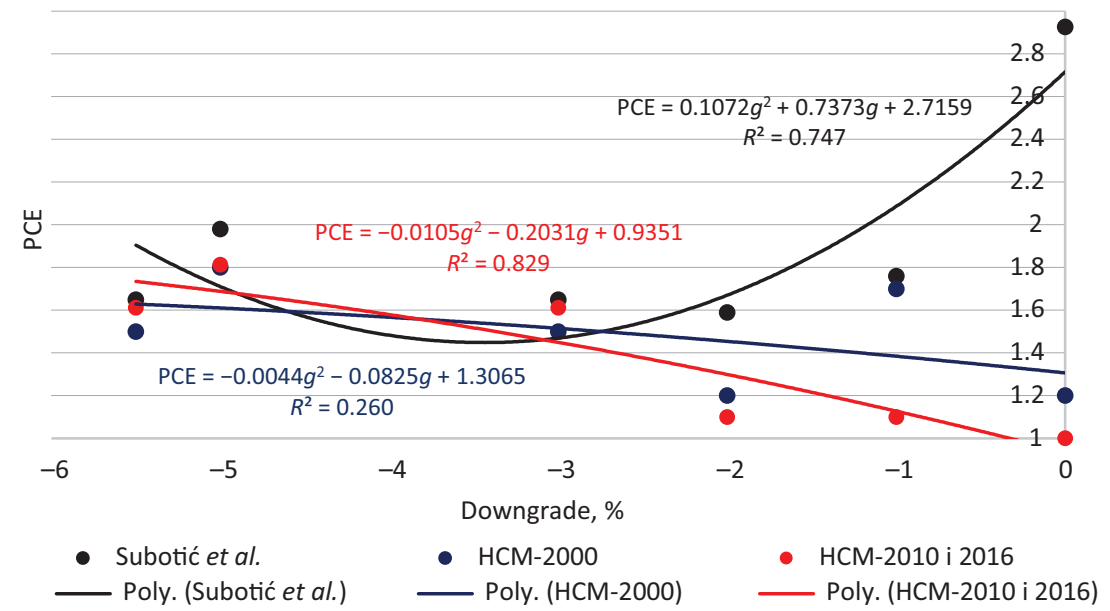

Figure 6. Comparative analysis of the PCE values with HCM-2000, HCM2010 and HCM-2016 
Thus, it can be concluded that for a downgrade value of $g \leq-3.00 \%$, the PCE values obtained by our research are higher than the values obtained in the US Highway Capacity Manuals.

It can also be noticed that the PCE values on the downgrade of two-lane roads increase for a longitudinal gradient value higher than $g=-3.00 \%$. The recommended PCE value on level terrain for commercial vehicles is just below 3.00, while generally increasing the downgrade, the value decreases to below 2.00. The fact is that traffic and road conditions are not the same in the USA and in particular location and that the values from HCM are inappropriate for local conditions. The real consequence would be that without calibration of the model for local conditions, the values would be lower than achievable in the procedures for capacity estimation.

\section{Conclusion}

The results obtained as a result of valid empirical research confirm the starting hypothesis of the paper that PCE values on the downgrade of two-lane roads are in complex functional dependence on the flow structure, driving and dynamic characteristics of vehicles and drivers, and especially on technical and exploitation characteristics of the roads. In addition, PCE values are not fixed but variable values and depend primarily on the functionally dependent indicators stated above. PCE values also depend on advancements in new vehicle manufacturing, as well as on driving and dynamic characteristics of vehicles. According to the model, the data obtained from the empirical research show lower PCE values compared to the recommended values from HCM for the downgrade from $g=0.00 \%$ to $g=-3.00 \%$.

The arithmetic means of the obtained PCE values for LV, HDV, BUS and AT vehicle categories are slightly higher on level terrain than on a downgrade, and PCE values range from 2.00 to 3.50 , except for AT, where the PCE value on level terrain is higher than 4.50. Deviation of PCE values for AT compared to other vehicle classes is significant for a downgrade value of $g=-5.00 \%$ and $g=-5.50 \%$. For all vehicle categories, the PCE value decreases with increasing the downgrade value from $g=0.00 \%$ to $g=-3.00 \%$, after which the PCE value starts to increase slightly, which is demonstrated by a positive correlation of $R^{2}=0.747$. The PCE values on the largest measured downgrade of $g=-5.50 \%$ ranges from 1.00 to 2.00 , for all vehicle classes. On the Doboj-Rudanka road section in free traffic flow conditions, slightly higher PCE values are obtained on level terrain compared to the
Passenger Car

Equivalents on Downgrades of Two-Lane Roads 
downgrade, where the PCE value for commercial vehicles is $P C E=2.972$ $(\approx 3.00)$. PCE values on the downgrade from $g=-1.00 \%$ to $g=5.50 \%$ for $\mathrm{LV}, \mathrm{HDV}, \mathrm{BUS}$ and AT vehicle categories range from 1.00 to 2.00 .

Comparing the PCE values obtained in this paper with HCM models (TRB, 2010, 2016), it can be concluded that PCE values significantly vary and that in case of increase in the downgrade values from $g=0.00 \%$ to $g=-3.00 \%$, the conducted research results in significantly higher PCE values for all commercial vehicles than those recommended in the HCM models. Based on the model given in Figure 7, it has been proved that until the downgrade reaches the value of $g=-3.00 \%$, the PCE curve continuously decreases, and only with a further increase in downgrade values, it gradually increases. The correlation coefficient is $R^{2}=0.747$, indicating large fluctuations in PCE values increasing downgrade values from $g=0.00 \%$ to $g=-5.50 \%$. Maximum PCE values are gained for level terrain ( $g=0.00 \%)$, and the difference of PCE values is smaller by increasing downgrade values for all vehicle classes. One of the limitations of this paper is that PCE values have been estimated only under free traffic flow conditions. Based on the analysis conducted so far, it has been noticed that the influence of commercial vehicles is much greater on the upgrade than the downgrade of two-lane roads under free traffic flow conditions.

The results obtained from this paper actualise the need for further research on PCE values for all traffic flow domains, thereby creating realistic preconditions for implementing the values into a local manual required for the procedures for practical capacity analysis and the Level of Service on the roads. In addition, the obtained results indicate the need for constant monitoring of free traffic flow and PCE values under normal and saturated flow conditions.

\section{Acknowledgement}

The paper is a part of the research conducted within project No. 19.032/961-58/19 "Influence of Geometric Elements of Two-lane Roads in Traffic Risk Analysis Models" supported by the Ministry of Scientific and Technological Development, Higher Education and Information Society of the Republic of Srpska. 


\section{REFERENCES}

Passenger Car

Equivalents

on Downgrades

Al-Kaisy, A. F., Hall, F. L., \& Reisman, E. S. (2002). Developing Passenger Car of Two-Lane Roads Equivalents for Heavy Vehicles on Freeways During Queue Discharge Flow. Transportation Research Part A: Polisy and Practice, 36(8), 725-742. https://doi.org/10.1016/s0965-8564(01)00032-5

Al-Kaisy, A., Jung, Y., \& Rakha, H. (2005). Developing Passenger Car Equivalency Factors for Heavy Vehicles During Congestion. Journal of Transportation Engineering, 131(7), 514-523. https://doi.org/10.1061/(ASCE)0733-947X(2005)131:7(514)

Al-Obaedi, J. T. S. (2016). Estimation of Passenger Car Equivalents for Basic Freeway Sections at Different Traffic Conditions. World Journal of Engineering and Technology, 4(2), 153-159. https://doi.org/10.4236/wjet.2016.42013

Anwaar, A., Van Boxel, D., Volovski, M., Anastasopoulos, P. Ch., Labi, S., \& Sinha, K. (2011). Using Lagging Headways to Estimate Passenger Car Equivalents on Basic Freeway Sections. Journal of Transportation of the Institute of Transportation Engineers, 2(1), 1-17.

Bhatt, M., \& Patel, P. (2017). Determination of Dynamic PCU in Ahmedabad City. International Journal of Advance Research and Innovative Ideas in Education, 3(2), 1179-1184.

Bham, G. H., \& Benekohal, R. F. (2004). A High Fidelity Traffic Simulation Model based on Cellular Automata and Car-Following Concepts. Transportation Research Part C: Emerging Technologies, 12(1), 1-32. https://doi.org/10.1016/j.trc.2002.05.001

Biswas, S., Chandra, S., \& Ghosh, I. (2017). Estimation of Vehicular Speed and Passenger Car Equivalent Under Mixed Traffic Condition Using Artificial Neural Network. Arabian Journal for Science and Engineering, 42(9), 4099-4110. https://doi.org/10.1007/s13369-017-2597-9

Brackstone, M., McDonald, M., \& Sultan, B. (1999). Dynamic Behavioral Data Collection Using an Instrumented Vehicle. Transportation Research Record: Journal of the Transportation Research Board, 1689, 9-16. https://doi.org/10.3141/1689-02

Chandra, S., \& Sikdar, P. K. (2000). Factors Affecting PCU in Mixed Traffic on Urban Roads. Road and Transport Research, 9(3), 40-50.

Cunagin, W. D., \& Messer, C. J. (1983). Passenger Car Equivalents for Rural Highways. Transportation Research Record, 905, 61-68.

Demarchi, S. H., \& Setti, J. R. (2003). Limitations of Passenger-Car Equivalent Derivation for Traffic Streams With More Than One Truck Type. Transportation Research Record, 1852(1), 96-104. https://doi.org/10.3141/1852-13

Elefteriadou, L., Torbic, D., \& Webster, N. (1997). Development of Passenger Car Equivalents for Freeways, Two-Lane Highways, and Arterials. Transportation Research Record: Journal of the Transportation Research Board, 1572(1), 51-58. https://doi.org/10.3141/1572-07 
Fadhloun, K., Rakha, H., Loulizi, A., \& Abdelkefi, A. (2015). Vehicle Dynamics Model for Estimating Typical Vehicle Accelerations. Transportation Research Record: Journal of the Transportation Research Board, 2491, 61-71. https://doi.org/10.3141/2491-07

Garbarino, S., Guglielmi, O., Sannita, W., Magnavita, N., \& Lanteri, P. (2018). Sleep and Mental Health in Truck Drivers: Descriptive Review of the Current Evidence and Proposal of Strategies for Primary Prevention. International Journal of Environmental Research and Public Health, 15(9), 1852. https://doi.org/10.3390/ijerph15091852

Gautam, A., Das, A., Rao, K. R., \& Tiwari, G. (2018). Estimation of PCE Values for Hill Roads in Heterogeneous Traffic Conditions. Transportation letters, 10(2), 83-91. https://doi.org/10.1080/19427867.2016.1190884

Giuffrè, O., Granà, A., Mauro, R., Silva, A. B., \& Chiappone, S. (2015). Developing Passenger Car Equivalents for Freeways by Microsimulation. Transportation Research Procedia, 10, 93-102. https://doi.org/10.1016/j.trpro.2015.09.059

Hoban, C. J. (1983). Towards a review of the concept of level of service for two-lane rural roads. Australian Road Research, 13(3).

Hoban, C. J. (1984). Bunching on two-lane rural roads. ARRB Internal report AIR359- Australian Road Research Board. Nunawading.

TRB (Transportation Research Board). (1985). Highway Capacity Manual. National Research Council. Special report 209. Washington D.C.

TRB (Transportation Research Board). (2000). Highway Capacity Manual. National Research Council. Washington D.C.

TRB (Transportation Research Board). (2010). Highway Capacity Manual. Volume 4. Applications Guide.

TRB (Transportation Research Board). (2016). Highway Capacity Manual. 6th Edition, Volume 2: Uninterrupted Flow. Washington D.C.

Krammes, R., \& Crowley, K. (1986). Passenger Car Equivalents for Trucks on Level Freeway Segments. Transportation Research Record, 1091, 10-17.

Krumins, I. V. (1988). Modeling headway distribution on two-lane highways. Report to Alberta Research Council. Edmonton.

Kumar, P., Arkatkar, S. S., Joshi, G., \& Dhamaniya, A. (2017). New Methodology for Estimating PCU on Multi-Lane Urban Roads Under Mixed Traffic Scenario Based on Area Occupancy. In Proc., Transportation Research Board 96th Annual Meeting, Washington, D.C.: Transportation Research Board, National Research Council.

Lay, M. G. (1984). Source Book for Australian Roads, 2nd edition. Australian Road Research Board. $551 \mathrm{p}$.

Nunić, Z. B., Ajanović, M., Miletić, D., \& Lojić, R. (2019). Determination of the Rolling Resistance Coefficient Under Different Traffic Conditions. Facta Universitatis, Series: Mechanical Engineering. https://doi.org/10.22190/FUME181116015N

Raj, P., Sivagnanasundaram, K., Asaithambi, G., \& Ravi Shankar, A. U. (2019). Review of Methods for Estimation of Passenger Car Unit Values of Vehicles. Journal of Transportation Engineering, Part A: Systems, 145(6), 04019019. https://doi.org/10.1061/jtepbs.0000234 
Rakha, H., \& Lucic, I. (2002). Variable Power Vehicle Dynamics Model for Estimating Truck Accelerations. Journal of Transportation Engineering, 128(5), 412-419. https://doi.org/10.1061/(asce)0733-947x(2002)128:5(412)

Sorensen, H. (1998). Determining Passenger Car Equivalents for Freeways. In TRB-Road Directorate Denmark, Proceedings of the Third International Symposium on Highway Capacity. Denmark, Copenhagen.

Stanković, M., Stević, Ž., Das, D. K., Subotić, M., \& Pamučar, D. (2020). A New Fuzzy MARCOS Method for Road Traffic Risk Analysis. Mathematics, 8(3), 457. https://doi.org/10.3390/math8030457

Subotić, M., Stević, B., Ristić, B., \& Simić, S. (2020). The Selection of a Location for Potential Roundabout Construction - A Case Study of Doboj. Operational Research in Engineering Sciences: Theory and Applications, 3(1), 41-56. https://doi.org/10.31181/oresta2002041s

Subotić, M., \& Tubić, V. (2017). Car Equivalents Dependence on the Longitudinal Road Gradient on Two-Lane Roads in Bosnia and Herzegovina. Promet-Traffic \& Transportation, 29(4), 401-409. https://doi.org/10.7307/ptt.v29i4.2226

Sumner, R., Hill, D., \& Shapiro, S. (1984). Segment Passenger Car Equivalent Values for Cost Allocation on Urban Arterial Roads. Transportation Research Part A, 18, 399-406. https://doi.org/10.1016/0191-2607(84)90014-1

Underwood, R. T. (1963). Traffic flow and bunching. Australian Road Research, 8(1). Australian Road Research Board.

Webster, N., \& Elefteriadou, L. (1999). A Simulation Study of Truck Passenger Car Equivalents (PCE) on Basic Freeway Sections. Transportation Research Part B: Methodological, 33(5), 323-336. https://doi.org/10.1016/s0965-8564(98)00036-6

Wolhuter, K. M. (1989). Headways on rural two-lane roads. Roads and Transport Technology Report DPVT 56, CSIR. Pretoria.

Yeung, J. S., Wong, Y. D., \& Secadiningrat, J. R. (2015). Lane-Harmonised Passenger Car Equivalents for Heterogeneous Expressway Traffic. Transportation Research Part A: Policy and Practice, 78, 361-370. https://doi.org/10.1016/j.tra.2015.06.001

Zhou, J., Rilett, L., Jones, E., \& Chen, Y. (2018). Estimating Passenger Car Equivalents on Level Freeway Segments Experiencing High Truck Percentages and Differential Average Speeds. Transportation Research Record, 2672(15), 44-54. https://doi.org/10.1177/0361198118798237
Marko Subotić, Željko Stević, Edis Softić, Veljko Radičević

Passenger Car Equivalents on Downgrades of Two-Lane Roads 